\title{
In Vivo Three-Dimensional Velocity Vector Imaging and Volumetric Flow Rate Measurements
}

Pihl, Michael Johannes; Stuart, Matthias Bo; Tomov, Borislav Gueorguiev; Hansen, Peter Møller; Nielsen, Michael Bachmann; Jensen, Jørgen Arendt

\section{Published in:}

Proceedings of the 2013 IEEE International Ultrasonics Symposium

Publication date:

2013

Document Version

Early version, also known as pre-print

Link back to DTU Orbit

Citation (APA):

Pihl, M. J., Stuart, M. B., Tomov, B. G., Hansen, P. M., Nielsen, M. B., \& Jensen, J. A. (2013). In Vivo ThreeDimensional Velocity Vector Imaging and Volumetric Flow Rate Measurements. In Proceedings of the 2013 IEEE International Ultrasonics Symposium IEEE.

\section{General rights}

Copyright and moral rights for the publications made accessible in the public portal are retained by the authors and/or other copyright owners and it is a condition of accessing publications that users recognise and abide by the legal requirements associated with these rights.

- Users may download and print one copy of any publication from the public portal for the purpose of private study or research.

- You may not further distribute the material or use it for any profit-making activity or commercial gain

- You may freely distribute the URL identifying the publication in the public portal 
Paper presented at the 2013 IEEE International Ultrasonics Symposium:

\section{In Vivo Three-Dimensional Velocity Vector Imaging and Volumetric Flow Rate Measurements}

Michael Johannes Pihl, Matthias Bo Stuart, Borislav Gueorguiev Tomov, Peter Møller Hansen, Michael Bachmann Nielsen and Jørgen Arendt Jensen

Center for Fast Ultrasound Imaging, Biomedical Engineering Group, Department of Electrical Engineering Ørsteds Plads Building 349, Technical University of Denmark, 2800 Kgs. Lyngby, Denmark. 


\title{
In Vivo Three-Dimensional Velocity Vector Imaging and Volumetric Flow Rate Measurements
}

\author{
Michael Johannes Pihl*, Matthias Bo Stuart*, Borislav Gueorguiev Tomov*, \\ Peter Møller Hansen ${ }^{\dagger}$, Michael Bachmann Nielsen ${ }^{\dagger}$ and Jørgen Arendt Jensen* \\ ${ }^{*}$ Center for Fast Ultrasound Imaging, Dept. of Elec. Eng., Bldg. 349, Technical University of Denmark, \\ 2800 Kgs. Lyngby, Denmark \\ $\dagger$ Department of Radiology, Copenhagen University Hospital, \\ 2100 Copenhagen, Denmark
}

\begin{abstract}
The three-dimensional (3-D) Transverse Oscillation (TO) method is used to obtain 3-D velocity vector estimates in two orthogonal planes. The method is suitable for a real-time implementation. Data are acquired using a Vermon 3.0 $\mathrm{MHz}$ $32 \times 32$ element 2-D phased array and the experimental ultrasound scanner SARUS. Measurements are conducted on a carotid artery flow phantom from Danish Phantom Design, and 20 frames are acquired with a constant flow rate of $16.7 \pm 0.17 \mathrm{~mL} / \mathrm{s}$ provided by a Shelley Medical Imaging Technologies CompuFlow 1000 system. The peak velocity magnitude in the vessel is found to be $52.3 \pm 8.1 \mathrm{~m} / \mathrm{s}$ compared to an expected peak velocity of $53.6 \pm 0.54$ $\mathrm{cm} / \mathrm{s}$. Based on the out-of-plane velocity component in the crosssectional plane, the estimated volumetric flow rates are 17.1 \pm 1.4 $\mathrm{mL} / \mathrm{s}$. The coefficient of variation is $8.3 \%$, and the bias is $2.2 \%$. An in vivo measurement of 3-D M-mode velocities is conducted over five heart beats. The peak systolic and end-diastolic velocities are $69 \pm 5.4 \mathrm{~cm} / \mathrm{s}$ and $7.9 \pm 5.5 \mathrm{~cm} / \mathrm{s}$ at the center of the vessel. For comparison, a commercial BK Medical ultrasound scanner using the spectral estimator yields $71.2 \mathrm{~cm} / \mathrm{s}$ and $7.70 \mathrm{~cm} / \mathrm{s}$, respectively. The results demonstrate that the 3-D TO method can estimate 3-D velocities in two crossed planes, volumetric flow rates, and 3-D velocities in vivo.
\end{abstract}

\section{INTRODUCTION}

Ultrasonic estimation of blood velocity plays an important role in the clinic when diagnosing cardiovascular diseases [1], [2]. Although several studies have shown that the velocity in the human circulatory system varies as a function of time and space with components in all three spatial dimensions [3]-[5], the estimation of blood velocities on most commercial scanners still relies on one-dimensional (1-D) axial estimators.

With 3-D velocity estimators, it is possible to perform 3-D vector flow imaging (VFI), and thereby estimate the true 3-D velocities, visualize complex flow patterns, and calculate volumetric flow rates without assumptions on out-of-plane motions. This paper employs the 3-D Transverse Oscillation (TO) method [6]-[8].

The purpose of this work is to investigate the TO method for estimating 3-D vector velocities in two orthogonal planes in a phantom mimicking the carotid artery. Based on the estimated velocities, volumetric flow rates are calculated. An example of 3-D M-mode velocities obtained in an in vivo carotid artery is also presented.

\section{The 3-D Transverse Oscillation Method}

The 3-D TO method employs a 2-D transducer and decouples the velocity estimation into three independent velocity components using a spatial quadrature approach [9], [10]. The three components are estimated simultaneously based on the same received data using a special autocorrelation approach [11] The field generation, beamforming, and velocity estimation for the 3-D Transverse Oscillation method are described in detail by Pihl et al. [8]. The method has been validated by simulation studies [6] and experimental flow-rig measurements in terms of velocity profiles [7] and obtained volumetric flow rates [8], which also demonstrates that the 3-D TO method is suitable for real-time processing.

\section{DATA ACQuisition AND PRocessing}

Data were acquired using a $3.0 \mathrm{MHz} 32 \times 32$ element 2-D phased array transducer (Vermon S. A., Tours, France) connected to the experimental ultrasound research scanner SARUS [12]. Data were sampled from all 1024 channels simultaneously and stored for offline processing.

Measurements were conducted on a flow phantom mimicking the carotid artery (Danish Phantom Design, Frederikssund, Denmark) connected to a CompuFlow 1000 system (Shelley Medical Imaging Technologies, Toronto, Canada), which ensured a constant flow rate of $16.7 \mathrm{~mL} / \mathrm{s}$.

The in vivo measurement was conducted by an experienced radiologist on the right carotid artery of a healthy 30 year old volunteer. To ensure FDA compliance, hydrophone measurements were performed using an AIMS III scanning tank system and the accompanying software (Onda, Sunnyvale, CA). The derated intensity values were: $\mathrm{MI}=0.86, I_{\mathrm{sppa}}=133 \mathrm{~W} / \mathrm{cm}^{2}$, and $I_{\text {spta }}=444 \mathrm{~mW} / \mathrm{cm}^{2}$. For comparison, a spectogram was recorded using a commercial Pro Focus UltraView scanner (BK Medical, Herlev, Denmark).

The stored raw RF data were matched filtered and beamformed using the Beamformation Toolbox 3 [13]. Mean stationary echo canceling (clutter filtering) was performed by subtracting the mean ensemble value of the $N_{l}$ lines prior to the velocity estimation. The velocity estimates were obtained using $N_{l}=32$ emissions per estimate. The estimated velocity components were rotated and scan converted according to the steering angle using linear interpolation. The discrimination 


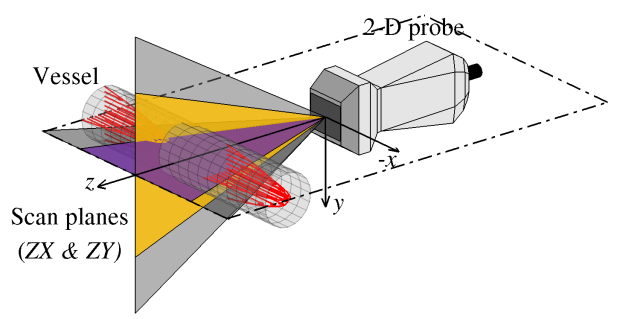

Figure 1. Imaging setup of the two scan planes $Z X$ and $Z Y$ for B-mode (gray) and VFI (purple and orange, respectively) and the M-mode line (coincides with the $z$ axis).

between flow and stationary objects was made by manually outlining the vessel boundaries based on the B-mode image.

Image lines were acquired in two planes $(Z X$ and $Z Y)$ as illustrated in Fig. 1. Each B-mode plane consists of 64 lines with an angle step of $1^{\circ}$ covering a field of view from $-31.5^{\circ}$ to $-31.5^{\circ}$. Each VFI plane consists of 9 lines. The VFI planes range from $-20^{\circ}$ to $20^{\circ}$ in steps of $5^{\circ}$. The system pulse repetition frequency was limited by hardware to $10 \mathrm{kHz}$, yielding a frame rate of $13 \mathrm{~Hz}$. The effective pulse repetition frequency for each flow line was $1.667 \mathrm{kHz}$.

From the plane forming a cross section of the vessel, volumetric flow rates were estimated by integrating the out-ofplane velocity component.

\section{RESUlts AND DisCUSSION}

\section{A. Carotid Artery Mimicking Phantom}

Fig. 2 shows one out of 20 acquired frames of estimated 3-D velocities in two orthogonal planes $(Z X$ and $Z Y)$ under constant flow conditions. The orientation of the transducer is so that the primary flow direction is close to the $-x$ direction. Fig. 3 shows the mean of the 20 frames as two orthogonal planes for all three velocity components and the velocity magnitude. Note that the two planes were not perfectly aligned along the center of the vessel.

Fig. 2(a), Fig. 2(b), and Fig. 3(a) show $v_{z}$, i.e. the velocity component parallel to the $z$ axis. This component is close to zero as expected based on the orientation of the imaging planes relative to the vessel.

Fig. 2(c), Fig. 2(d), and Fig. 3(b) show $v_{y}$. This component is small at the center of the vessel in both planes. There are some areas of higher velocities at the boundaries. These may represent rotational flow components, but may also be due to boundary effects.

The velocity component $v_{x}$ is shown in Fig. 2(e), Fig. 2(f), and Fig. 3(c). The largest component is at the center and smaller values are present at the vessel boundaries. An overall parabolic and 2-D circular symmetrical parabolic shape of the flow can be recognized in the $Z X$ and $Z Y$ planes, respectively. However, as the tubes are bending prior to inflow in the phantom, complete fully developed flow can not be expected, and rotational flow components are likely to be present.

Fig. 3(d) displays the velocity magnitude. The velocity profile is the same as for $v_{x}$. It can be noted that due to the high

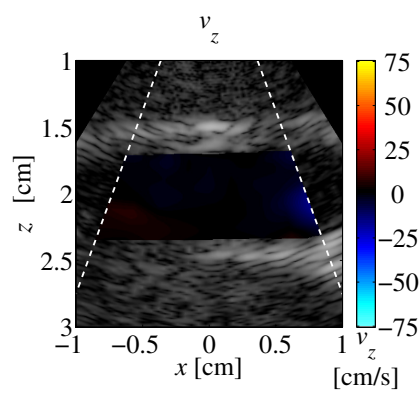

(a)

$v_{y}$

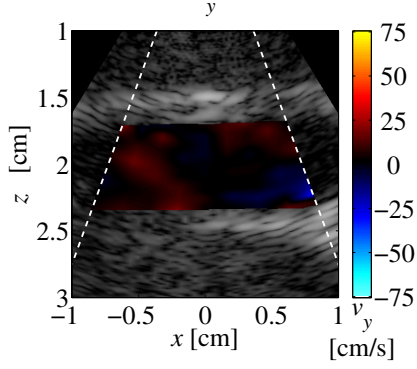

(c)

$v_{x}$

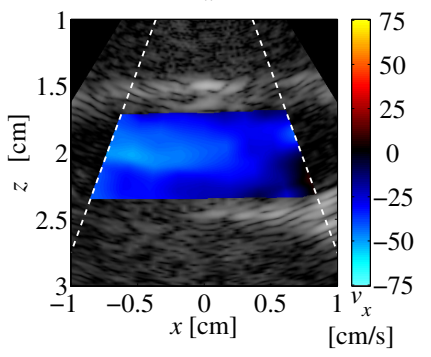

(e)

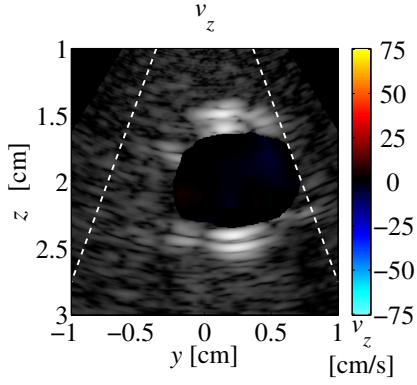

(b)

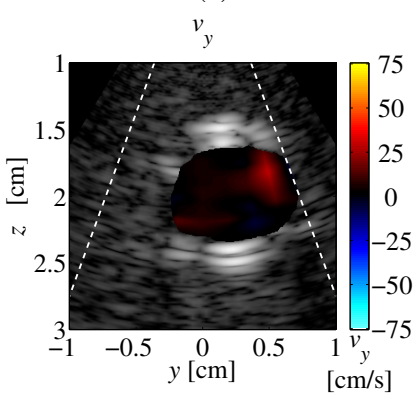

(d)

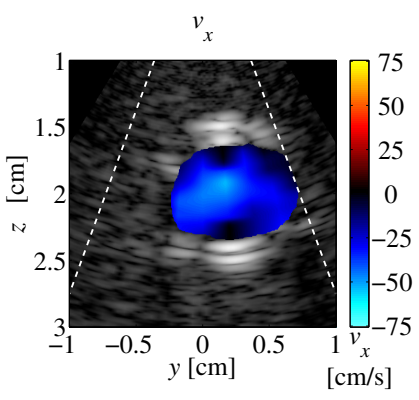

(f)
Figure 2. Shows the three spatial velocity obtained from the carotid mimicking phantom for the $Z X$ (left column) and the $Z Y$ plane (right column) where (a) \& (b) are $v_{x}$, (c) \& (d) are $v_{y}$, and (e) \& (f) are $v_{y}$. The white dashed lines indicate the field of view of the velocity estimates. Note that the range of the colorbar for $v_{z}$ is five times smaller than for the other components The dynamic range of the B-mode images is $65 \mathrm{~dB}$.

reflections in the vessel walls, the velocity estimates near the boundaries get suppressed.

At the center of the vessel, $v_{z}=-1.9 \pm 1.0 \mathrm{~cm} / \mathrm{s}, v_{y}=4.1 \pm 7.8$ $\mathrm{cm} / \mathrm{s}, v_{x}=-45.0 \pm 5.3 \mathrm{~cm} / \mathrm{s}$, and $|v|=45.6 \pm 5.6 \mathrm{~cm} / \mathrm{s}$. The expected velocity magnitude based on the flow rate and the vessel geometry is $53.6 \mathrm{~cm} / \mathrm{s}$. The apparent underestimation may be due to the fact that the flow is not fully developed, hence, a lower peak velocity is probable. In addition, the spacing of the VFI lines is large, and the area with the highest velocity may be missed.

As the out-of-plane velocity component can be measured in a cross sectional plane of the vessel with the 3-D TO method, volumetric flow rates can be estimated. For the case presented here, $v_{x}$ in the $Z Y$ plane is summed over the vessel lumen and gives $17.1 \pm 1.4 \mathrm{~mL} / \mathrm{s}$ compared to the desired $16.7 \mathrm{~mL} / \mathrm{s}$ set for the piston flow pump. The coefficient of variation is $8.3 \%$ and the bias is $2.2 \%$. 


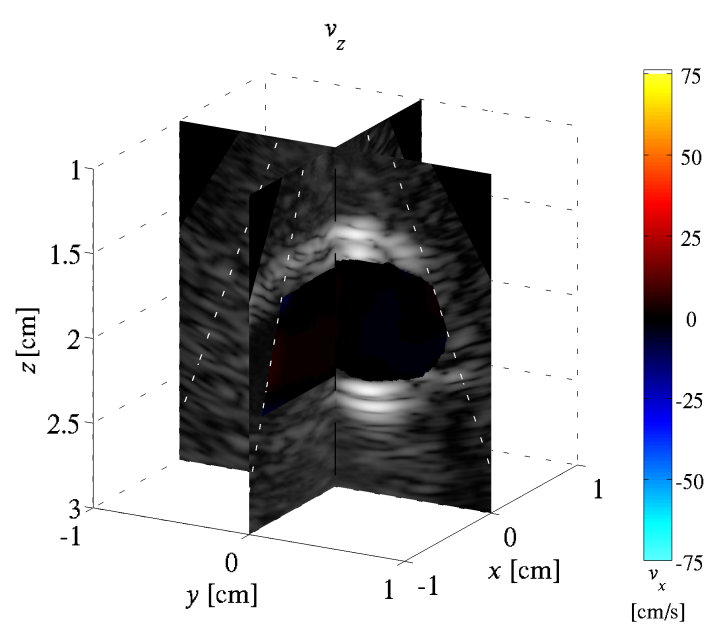

(a)

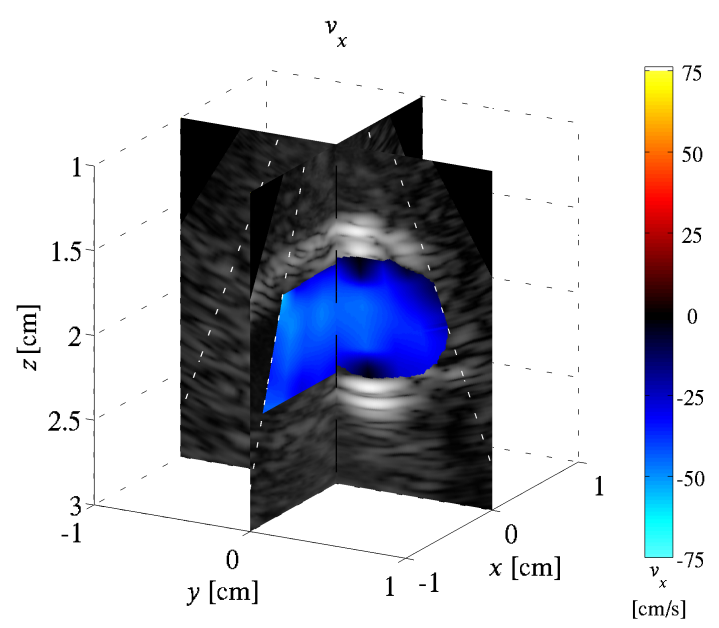

(c)

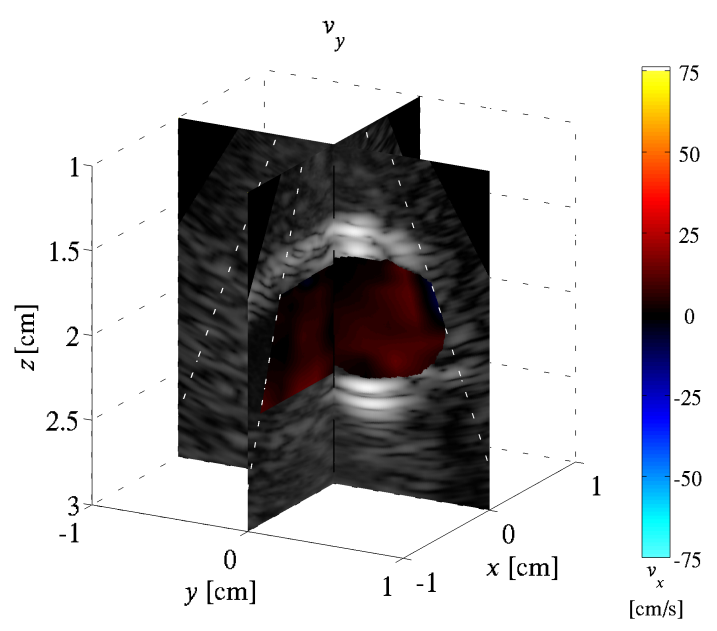

(b)

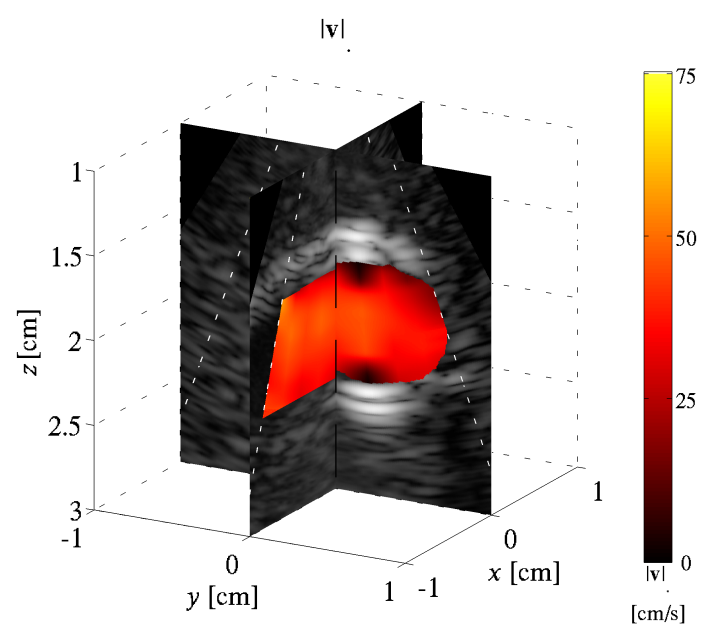

(d)

Figure 3. Two orthogonal planes of the three velocity components and the velocity magnitude. The results shown are the mean of the 20 acquired frames. The white dashed lines indicate the field of view of the velocity estimates.

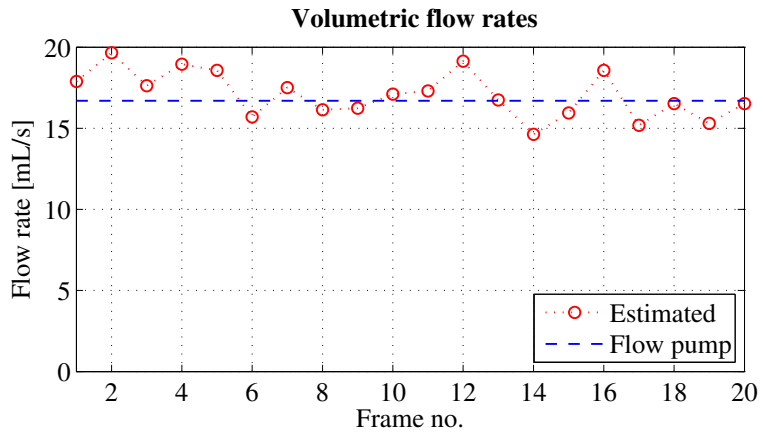

Figure 4. Volumetric flow rates estimated using the 3-D TO method in comparison to the set flow rate of the piston pump.

\section{B. In Vivo Carotid Artery}

M-mode 3-D velocities were acquired in an in vivo carotid artery along the center line of the two image planes. Fig. 5 shows one estimate of the 3-D velocities represented by arrows at the center of the vessel for a time point at peak systole.

Fig. 6 shows five heart beats of the three velocity components and the velocity magnitude. For comparison, the peak systolic $(71.2 \mathrm{~cm} / \mathrm{s})$ and end-diastolic $(7.70 \mathrm{~cm} / \mathrm{s})$ velocities obtained from the spectral estimator on the commercial scanner are shown as dashed lines. The mean of the maximum velocity magnitudes during each heart beat is $69 \pm 5.4 \mathrm{~cm} / \mathrm{s}$. The end-diastolic velocity is calculated as the mean of the last 10 velocity estimates (taken over $133 \mathrm{~ms}$ ) in each of the five cardiac cycles. The result is $7.9 \pm 5.5 \mathrm{~cm} / \mathrm{s}$. It should be noted that the two measurements could not be acquired simultaneously, due to the use of two different transducers and scanners. Additionally, the site of investigation may be slightly different. Nonetheless, the temporal changes are similar to the spectrogram obtained from the commercial scanner. It is visible underneath the velocity magnitude trace in the bottom graph. The results demonstrate that the estimated 3-D velocities are 


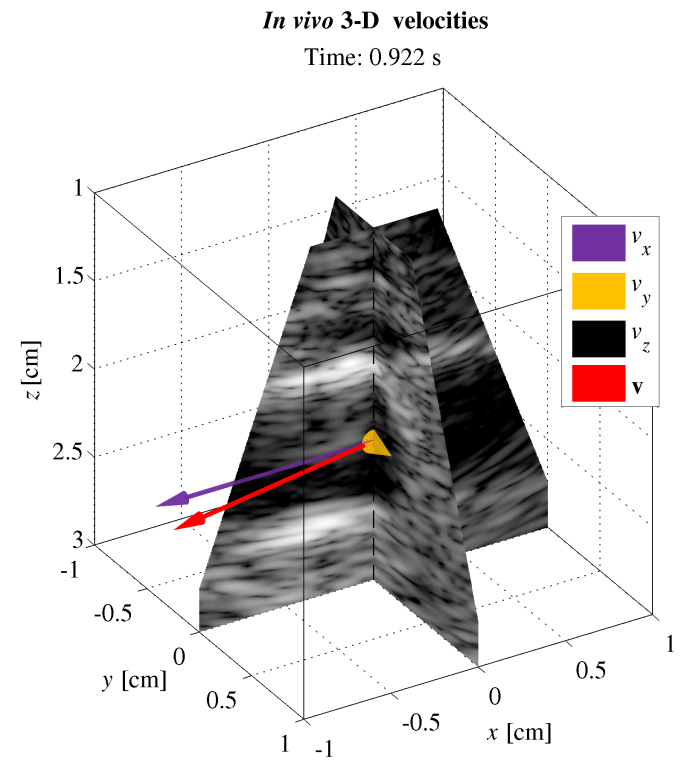

Figure 5. 3-D velocity vectors at the center of a carotid artery in a healthy 30 year old volunteer during peak systole. The velocity components and the resulting velocity vector are represented by arrows. The color coding corresponds to the vector components and the full vector. Note that $v_{z}$ is so small that it is not visible. See the same time instance (0.992 s) in Fig. 6.

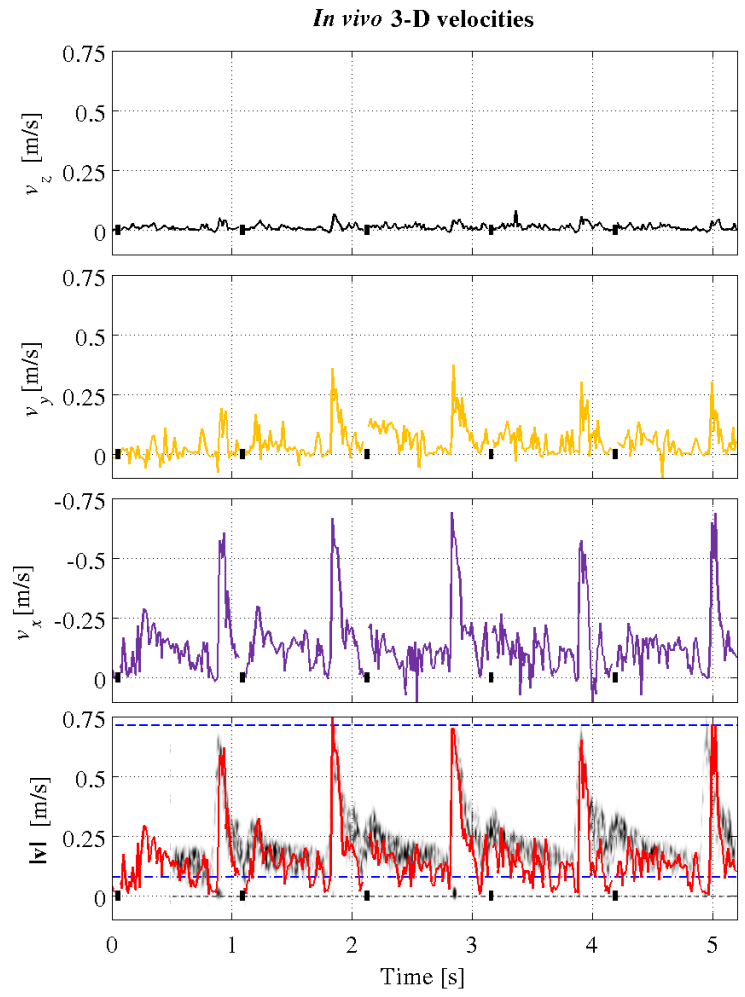

Figure 6. Temporal variations in the $3-\mathrm{D}$ velocity components and the velocity magnitude over five heartbeats. Note that no temporal filter has been applied. The black squares indicate time periods used for B-mode acquisition. On the bottom graph, the dashed blue line indicates the peak systolic velocity measured with a commercial ultrasound scanner, and the blue dash-dotted line indicates the end-diastolic velocity. Also, the obtained spectrogram (not acquired simultaneously) is visible underneath the velocity magnitude trace for illustrative purposes. The spectrogram has been scaled and adjusted in time to obtain the best match. similar to the clinically estimated values.

\section{CONCLUSION}

The results demonstrate that 3-D velocities can be estimated in two orthogonal planes using the 3-D Transverse Oscillation method. Based on the out-of-plane velocity component for a cross-sectional plane, it is possible to estimate volumetric flow rates. The results also demonstrate that the 3-D TO method is suitable for obtaining in vivo estimates of 3-D velocities. Using ultrasound with the 3-D TO method, both data acquisition and processing can be done in real-time allowing for bed-side examination. The estimation of true velocity magnitudes and quantitative estimates of volumetric flow rates are expected to have significant impact on diagnoses of cardiovascular diseases. Furthermore, the visualization of complex 3-D flow patterns will provide an increased understanding of human blood flow and may reveal pathological information.

\section{ACKNOWLEDGMENT}

This work was supported by grant 024-2008-3 and grant 82-2012-4 from the Danish Advanced Technology Foundation and by BK Medical Aps.

\section{REFERENCES}

[1] D. H. Evans, J. A. Jensen, and M. B. Nielsen, "Ultrasonic colour Doppler imaging," Interface Focus, vol. 1, no. 4, pp. 490-502, August 2011.

[2] C. Arning, B. Widder, G. M. von Reutern, H. Stiegler, and M. Görtler, "Revison of DEGUM Ultrasound Criteria for Grading Internal Carotid Artery Stenoses and Transfer to NASCET Measurement," Ultraschall in Med, vol. 31, no. 3, pp. 251-257, 2010.

[3] P. J. Kilner, G. Z. Yang, R. H. Mohiaddin, D. N. Firmin, and D. B Longmore, "Helical and retrograde secondary flow patterns in the aortic arch studied by three-directional magnetic resonance velocity mapping," Circulation, vol. 88, no. 5, pp. 2235-2247, 1993.

[4] C. Taylor, T. Hughes, and C. Zarins, "Finite element modeling of blood flow in arteries," Computer methods in applied mechanics and engineering, vol. 158, no. 1, pp. 155-196, 1998.

[5] K. L. Hansen, J. Udesen, C. Thomsen, J. A. Jensen, and M. B. Nielsen, "In vivo validation of a blood vector velocity estimator with MR angiography," IEEE Trans. Ultrason., Ferroelec., Freq. Contr., vol. 56, no. 1, pp. 91-100, 2009

[6] M. J. Pihl and J. A. Jensen, "3D velocity estimation using a 2D phased array," in Proc. IEEE Ultrason. Symp., 2011, pp. 430-433.

[7] _ - "Measuring 3D velocity vectors using the transverse oscillation method," in Proc. IEEE Ultrason. Symp., 2012, pp. 1881-1885.

[8] M. J. Pihl, M. B. Stuart, B. G. Tomov, J. M. Hansen, M. F. Rasmussen, and J. A. Jensen, "Preliminary examples of 3D vector flow imaging," in Proc. SPIE Med. Imag., vol. 8675, 2013, pp. 86750H-1-86750H-12.

[9] J. A. Jensen and P. Munk, "A New Method for Estimation of Velocity Vectors,” IEEE Trans. Ultrason., Ferroelec., Freq. Contr., vol. 45, pp. 837-851, 1998

[10] M. E. Anderson, "Multi-dimensional velocity estimation with ultrasound using spatial quadrature," IEEE Trans. Ultrason., Ferroelec., Freq. Contr., vol. 45, pp. 852-861, 1998.

[11] J. A. Jensen, "A New Estimator for Vector Velocity Estimation," IEEE Trans. Ultrason., Ferroelec., Freq. Contr., vol. 48, no. 4, pp. 886-894, 2001.

[12] J. A. Jensen, H. Holten-Lund, R. T. Nilsson, M. Hansen, U. D. Larsen, R. P. Domsten, B. G. Tomov, M. B. Stuart, S. I. Nikolov, M. J. Pihl, Y. Du, J. H. Rasmussen, and M. F. Rasmussen, "SARUS: A synthetic aperture real-time ultrasound system," IEEE Trans. Ultrason., Ferroelec., Freq. Contr., p. In press, 2013.

[13] J. M. Hansen, M. C. Hemmsen, and J. A. Jensen, "An object-oriented multi-threaded software beamformation toolbox," in Proc. SPIE Med Imag., vol. 7968, March 2011, pp. 79680Y 1-9. [Online]. Available: http://dx.doi.org/10.1117/12.878178 